\title{
Assessment of the Effect of the Rate of Internal Displaced Persons on Food Price Variations Time Series from Year 2009 to 2020 in Badakhshan, Afghanistan.
}

\author{
Uba Matthew Ndubuisi
}

30 January, 2022

\section{Contents}

2.0 METHODOLOGY 2

2.1 Discription of Data . . . . . . . . . . . . . . . . . . . . . . . 2

2.2 Method of Data Collection . . . . . . . . . . . . . . . . . . . . . 2

2.3 Method of Data Analysis . . . . . . . . . . . . . . . . . . . . . 3

3.0 DISCUSSIONS
3

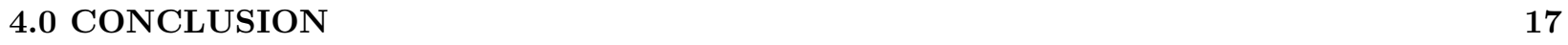

$\begin{array}{ll}\text { 5.0 REFERENCES } & 17\end{array}$

Author: Uba Matthew Ndubuisi

(M. Sc.) Environmental Science - Global Change and Sustainability

Thanks: Professor Gaetan Carlo

Affiliation: Department of Environmental Science, Informatics and Statistics

Ca'Foscari University of Venice, Venezia (VE), Italy (IT).

\begin{abstract}
Internally displacement of persons has been a major factor leading to food insecurity in several countries, especially when their source of livelihood depends on agriculture. This displacement can be caused by conflict, insurgency, or environmental disaster. Because of the high rate of displaced persons, there is less human capacity to farm, which leads to less production of agricultural produce. As supply of farm produce becomes limited, prices of food increases. This effect was evident from the analysis of the secondary data using R-Programming, sourced from the worldbank microdata library and the Internal Displacement Monitoring Center Global Internal Displacement Database (IDMC). Variables which include Year (2009 to 2020 ), Food Price Index from 2009 to 2020, Conflict stock displacement from 2009 to 2020 and Environmental Disaster Displacement from 2009 to 2020 were extracted from the dataset for analysis. Their trends were observed using time series. Regression results revealed that food price was increasing significantly with respect to time with a p-value of $2.2 \mathrm{e}-16<0.05$. Also, the internally displaced persons caused by conflict has a significant impact on the increasing food price with a p-value of $7.137 \mathrm{e}-08<0.05$, but the internally displaced persons caused by environmental disaster has no significant impact on the increasing food price.Therefore, it is
\end{abstract}


obvious that increasing rate of internally displaced persons can have a drastic impact on food price which can result to inflection rate.

Keywords: Food Price Index, Internal Displaced Persons, Environmental Disaster, Conflict

\subsection{INTRODUCTION}

The highest economic impact is associated to the provision of food (Tharanga, 2021) and the source of food supply for countries irrespective of how developed they are is agriculture (Ahmad, 2018). Afghanistan major source of food security is agriculture and more than 60 percent of Afghans depend on agriculture as their source of income (Massarath, 2019). The crops which they produce are different classes of cereals, fruits and livestock (Ahmad, 2018). Unfortunately, an estimate of 400,000 Afghans over the past 10 years whose livelihood is from agriculture has been internally displaced by events of conflicts and environmental disasters (Massarath, 2019).

In Central Africa countries between 2013 and 2017, approximately 40 percent of impact on food security was because of internal displacement (Tharanga, 2021). Mali and Nigeria where there is high level of conflict and insurgency results to internally displaced persons, and farmers who receives fertilizers from the government or purchase from suppliers no longer gain access to fertilizers and other farm resources like seedlings for farm production. Those involved in livestock no longer gain access to feeds to breed their livestock because of fear and most of their livestock were stolen due to the situation of insecurity. As displacement lasts, traders increase prices of food due to limited supplies of farm products (Mwangi et al, 2014).

Environmental situation leading to internally displace persons is also pronounced. In Somalia's wide drought between 2017 and 2018 lead to 892000 new displacement which left rural communities unable to cultivate and live off their lands (Tharanga, 2021).

Therefore, this project will assess the effect at which the rate of internally displace persons caused by the two events of conflict and environmental disaster on the annual average food price index from year 2009 to 2020 in Afghanistan and the analysis of the time series for the food price index.

\subsection{METHODOLOGY}

\subsection{Discription of Data}

Numerical dataset (RTFP_mkt_2021-12-17.csv) were sourced from the World Bank Microdata Library Congo, Rep. - Monthly food price estimates by product and market, 01/2007 to 12/2021 (Congo, Rep., 9 markets), Version 2021-12-21 worldbank.org. Source: https://microdata. worldbank/index.php/catalog/4226/get-microdata and datasets (IDMC_Internal_Displacement_ConflictViolence_Disaster_2008_2020) and (IDMC_Internal_Displacement_Disaster_Event_2008_2020) were also sourced from the Internal Displacement Monitoring Center Global Internal Displacement Database (IDMC) intrnal-displacement.org. Sources: https://www.internal-displacement.org/database/displacementdata

The new dataset (Afghanistan_timeseries.csv) was extracted from the original dataset (RTFP_mkt_202112-17.csv) and (Afghanistan_displacement.csv) is extracted from the original dataset (RTFP_mkt_202112-17.csv, (IDMC_Internal_Displacement_ComflictViolence_Disaster_2008_2020.csv and IDMC_Internal_Displacement_ and ).

\subsection{Method of Data Collection}

The Food Price Index (FPI) estimates in Afghanistan are generated using a machine-learning approach that imputes ongoing sub national price surveys, often with accuracy like direct measurement of prices 
(World Bank). It is a measure of the monthly change in international prices of a basket of food commodities. The Index consists of the average of five commodity group price indices weighted with the average export shares of each of the groups. It is composed of commodity quotations and updated monthly (FAO, 2021).

Internally Displaced Persons (IDPs) in Afghanistan are persons or groups of persons who have been forced or obliged to flee or to leave their homes or places of habitual residence, in particular because of or to avoid the effects of armed conflict, situations of generalized violence, violations of human rights or natural or human-made disasters, and who have not crossed an internationally recognized State border (IDMC, 2013). It is collected through the IDMC's displacement data model. The IDP data was collected in two groups, those caused by conflict and violence and those caused by environmental disaster.

\subsection{Method of Data Analysis}

Different statistical models were applied to analyze the variables (Open_food_price_index: monthly change in international prices of a basket of food commodities in Afghanistan from January 2009 to December 2020 , Conflict_stock_displacement: annual average internally displaced persons caused by Conflict and Violence from 2009 to 2020, Environmental_disaster_displacement: annual average internally displaced persons caused by environmental disaster from 2009 to 2020, and Annual_foodprice_index: Annual average for food price index from 2009 to 2020) using R Programming. Histogram was employed for empirical frequencies (f) across the four variables. Plot Box was used to determine the mean in the four variables. The trends food price index, conflict displacement and environmental disaster displacement were analyze using the Time Series Plot and were filtered using Kern smooth. Finally, the following assumptions were validated using Simple Linear Regression Model; if the food price index is increasing with time, if the displacement coursed by conflict has influence on the food price index, if the displacement coursed by environmental disaster has influence on the food price index.

\subsection{DISCUSSIONS}

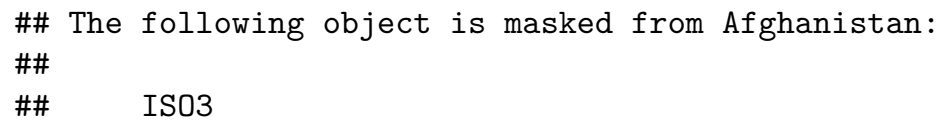

Results from the analysis reveals that from year 2009 to 2020, the monthly food price index shows the highest frequency between 1,1 to 1.15 which fall within the rang of the frequency 0.9 to 1.2 of the annual food price index which was calculated from the monthly food price index. Their respective mean are 1.1466667 and 1.0633333 which seams close. 


\section{Monthly Food Price Index Histogri Annual Food Price Index Histogra}
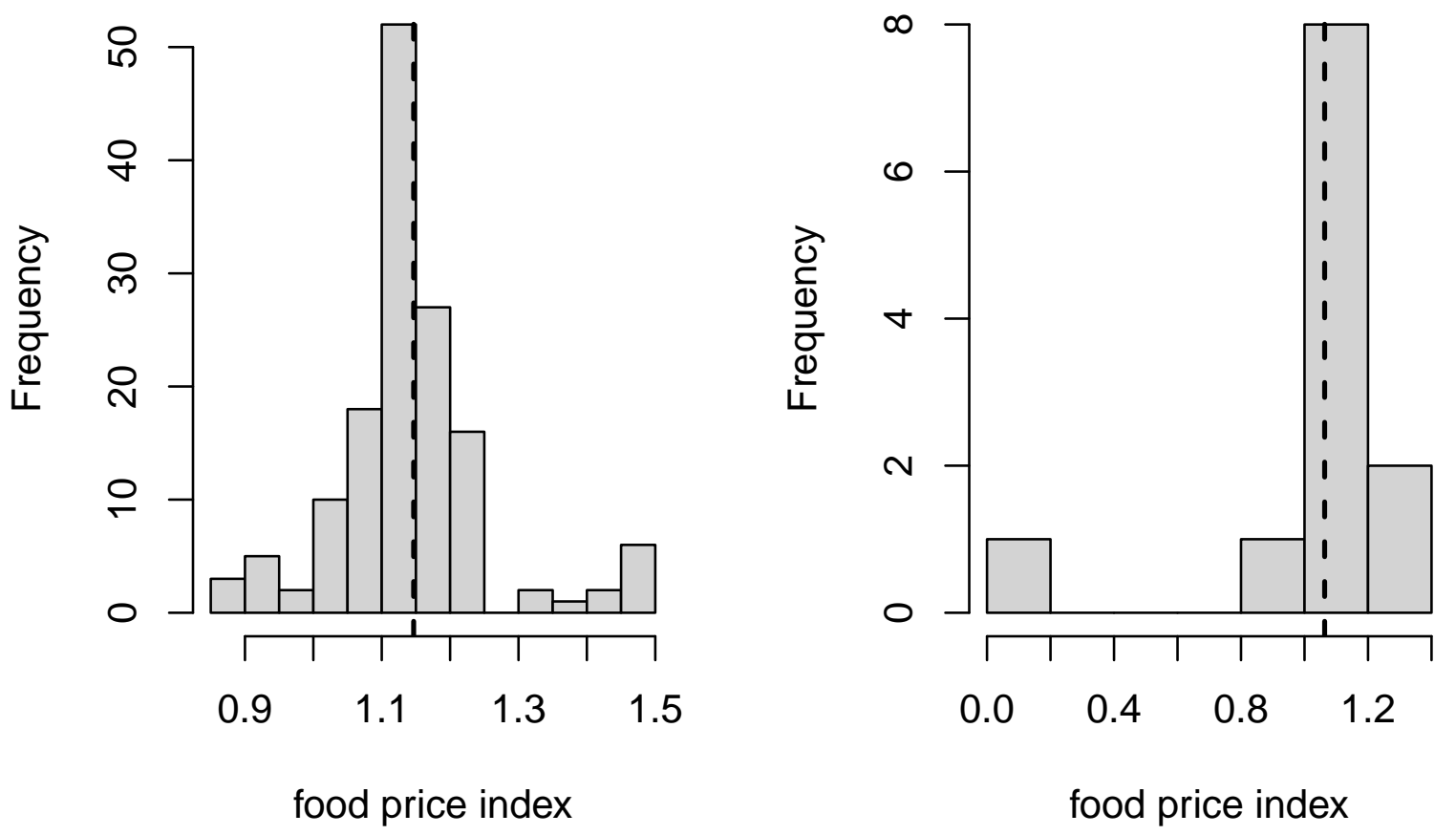

Figure 1: Histograms showing spartial distribution of monthly and annual food price index 

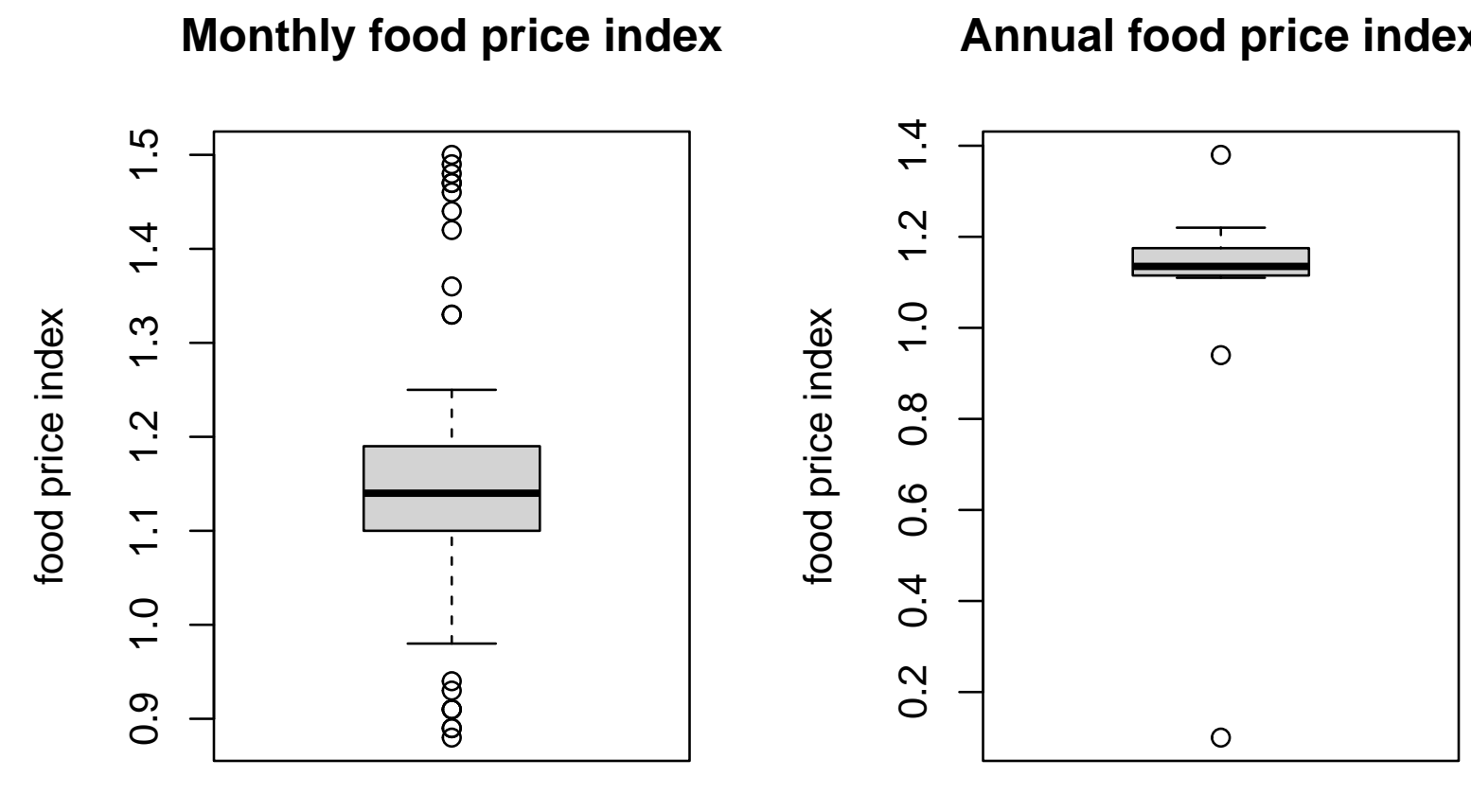

Figure 2: Boxplot for monthly and annual food price index showing their mean and outliers

Also, Conflict stock displacement with the highest frequency from 0 to 500,000 persons displaced and environmental disaster displacement with the highest frequency at 0 to 100,000 persons displaced has their respective means as $1.3481667 \times 10^{6}$ and $7.177725 \times 10^{4}$. 
Conflict Displacement Histograr

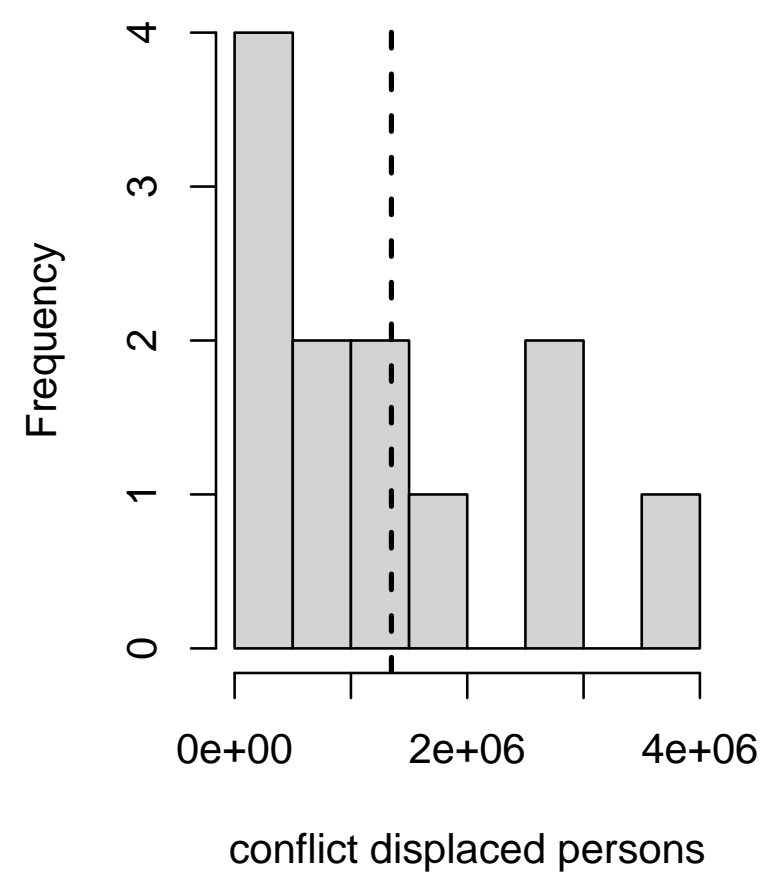

\section{Env. Displacement Histogram}

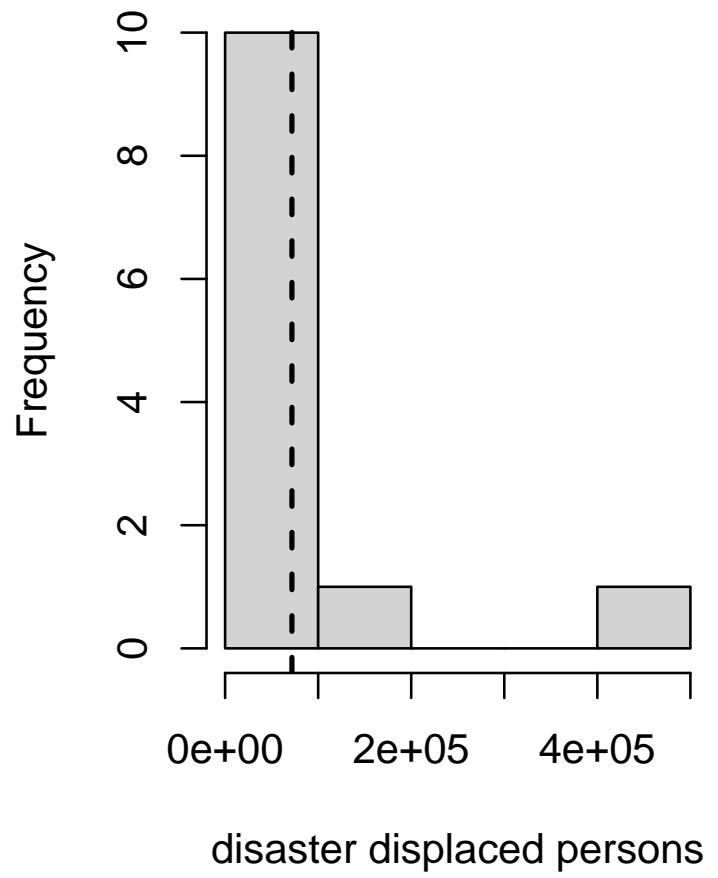

Figure 3: Histograms showing spartial distribution of persons displaced by conflict and environmental disaster 


\section{Conflict displaced persons}

\section{Env. Disaster Displaced person:}
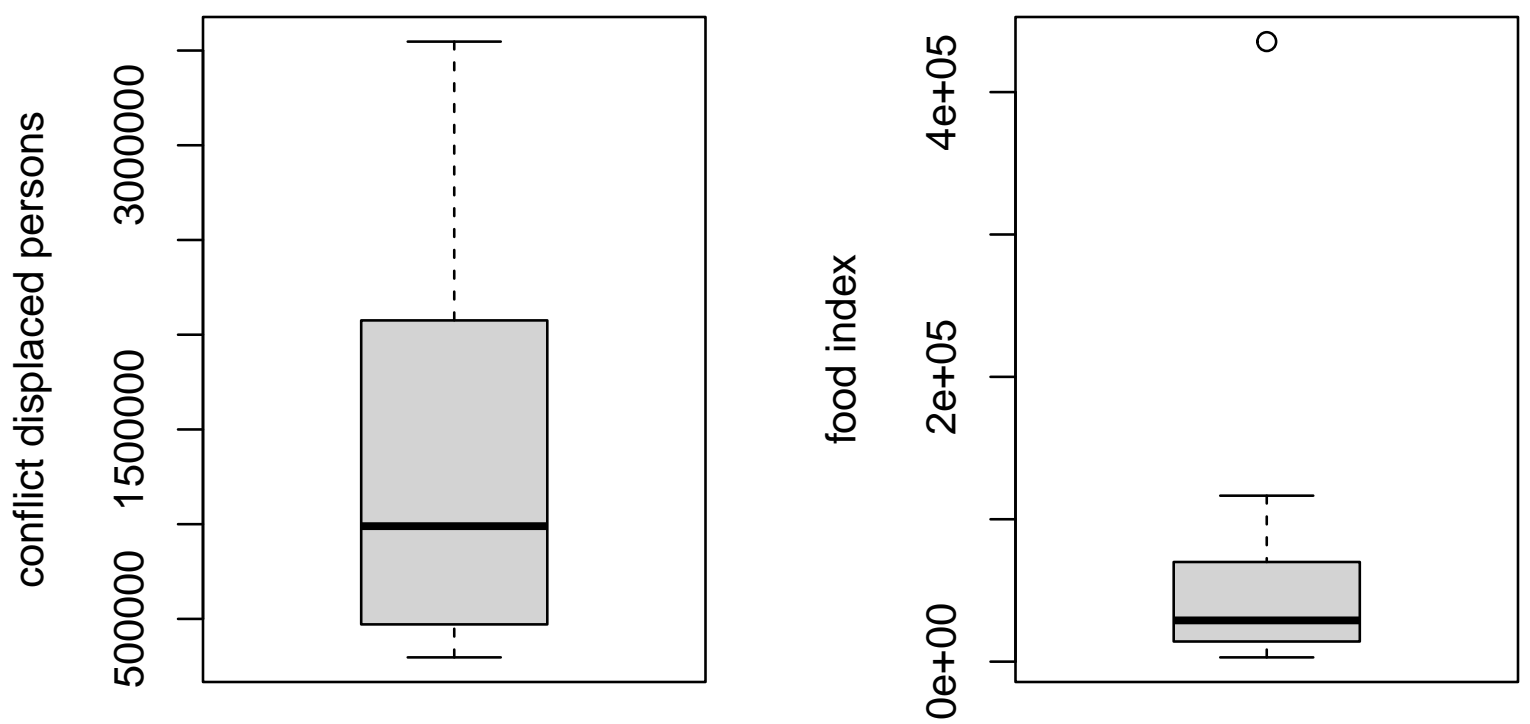

Figure 4: Boxplot for conflict stock displacement and environmental disaster displacement showing their mean and outliers

From the time series plot for food price index (Figure 5), it shows an increase in trend from year 2010 to the end of year 2013 which later had a little decline from $1.2(\max )$ to $1.05(\mathrm{~min})$ between the end of 2013 to mid 2016 which then took a gradual rise from take 2019 and an abrupt increase to the end of 2020 . This changes may be suspected to be caused by the events of humanitarian aid. The conflict stock displacement also shows an increasing trend of persons being displaced from 2009 to 2020 (Figure 6). The slight decline corresponds to the event of humanitarian aid which also affected the food price to experience slight decrease.It also indicate a period of peace in Afghanistan. The trend for environmental disaster displacement shows a non homogeneity from 2009 to 2016, the has a rise to 2081 and declined back through 2020 (Figure 7).This may be due to environmental disaster events does not last for too long.

\#\# KernSmooth 2.23 loaded

\#\# Copyright M. P. Wand 1997-2009 


\section{Food Price Index monthly Time Series}

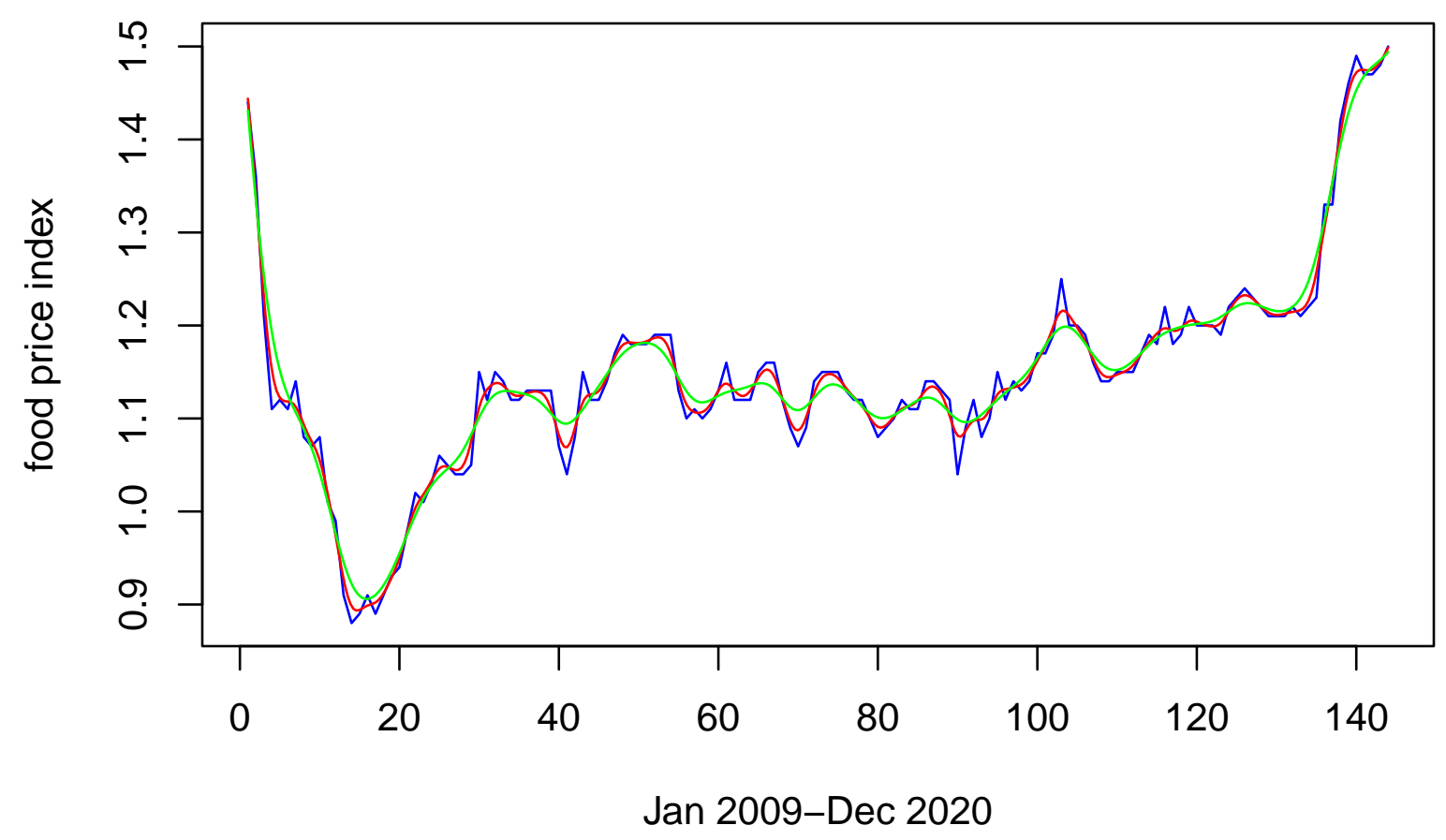

Figure 5: Time series for food price index in Afghanistan from January 2009 to December 2020 


\section{Conflict Displacement Yearly Time Series}

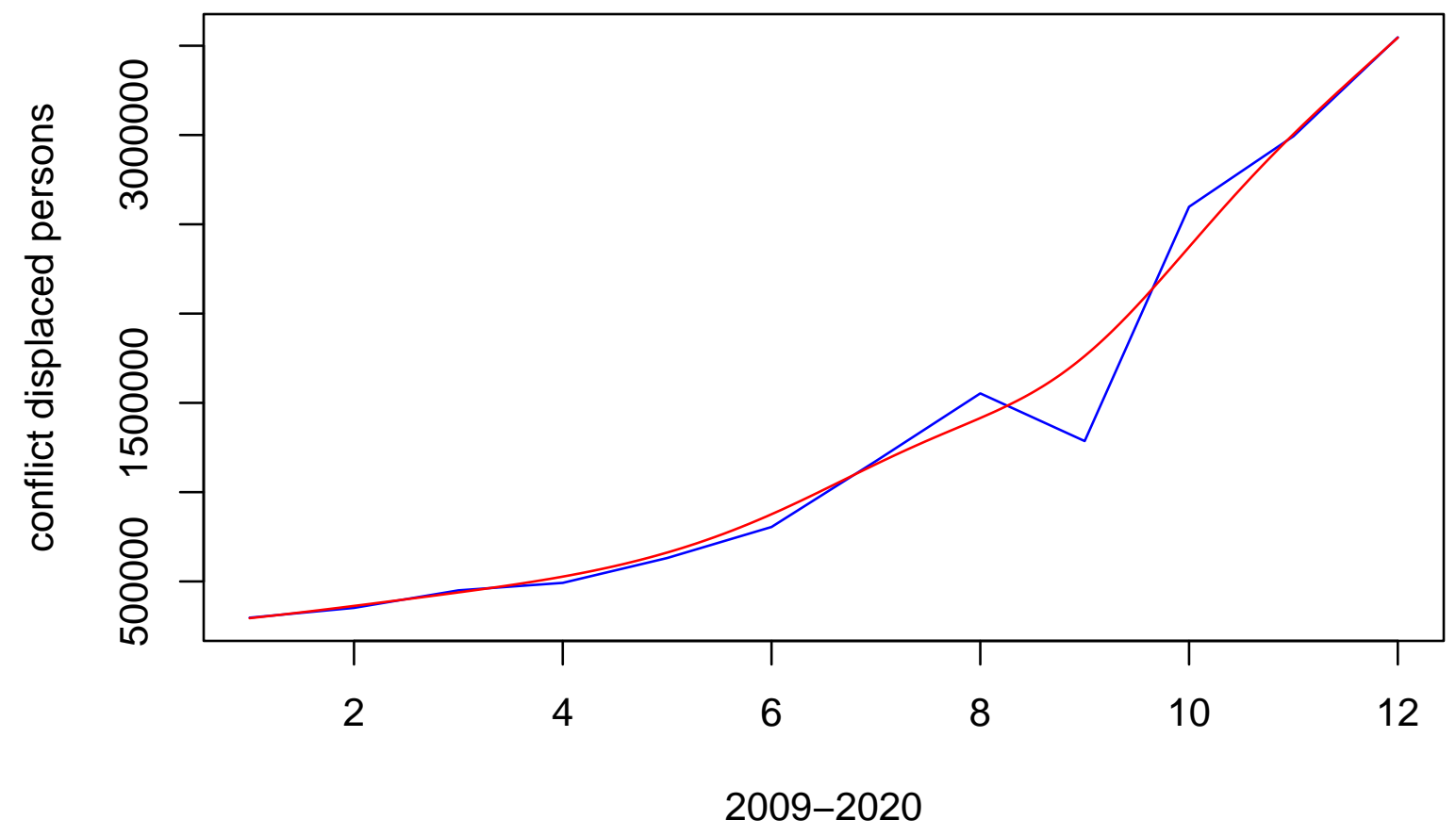

Figure 6: Time series for Conflict stock displacement in Afghanistan from year 2009 to 2020 


\section{Env. Disaster Displacement Time Series}

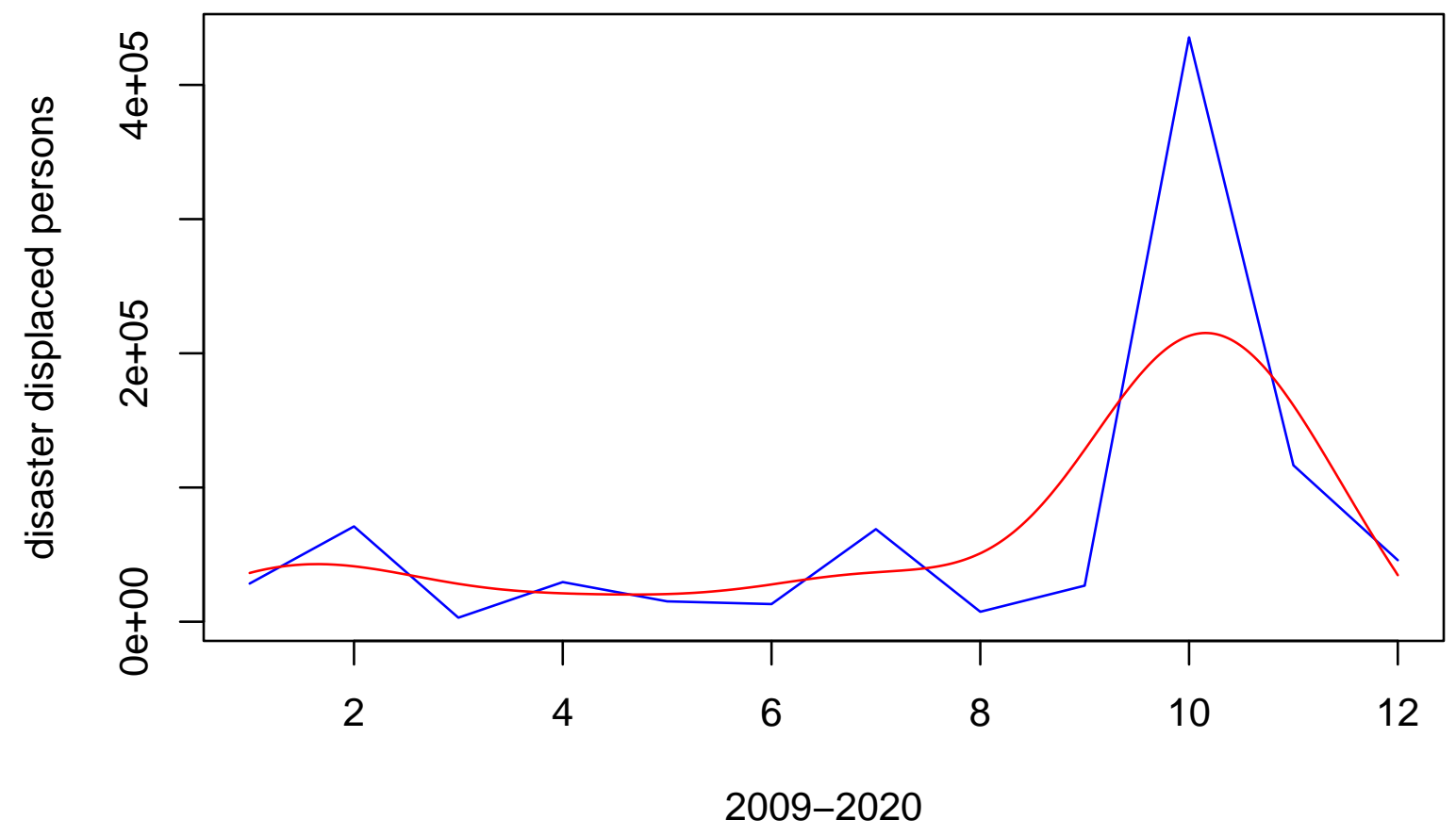

Figure 7: Time series for Environmental disaster displacement in Afghanistan from year 2009 to 2020

The correlation value of $\mathbf{0 . 6 2 6 4 7 3}$ shows that there is a strong positive correlation between the two variables. The linear regression is estimated by fitting the regression analysis equation.

$$
Y_{i}=\beta_{0}+\beta_{1} x_{i}+\epsilon_{i}
$$

Viewing the fitted linear regression model: 


\section{Linear Regression for Food Price Index and Time}

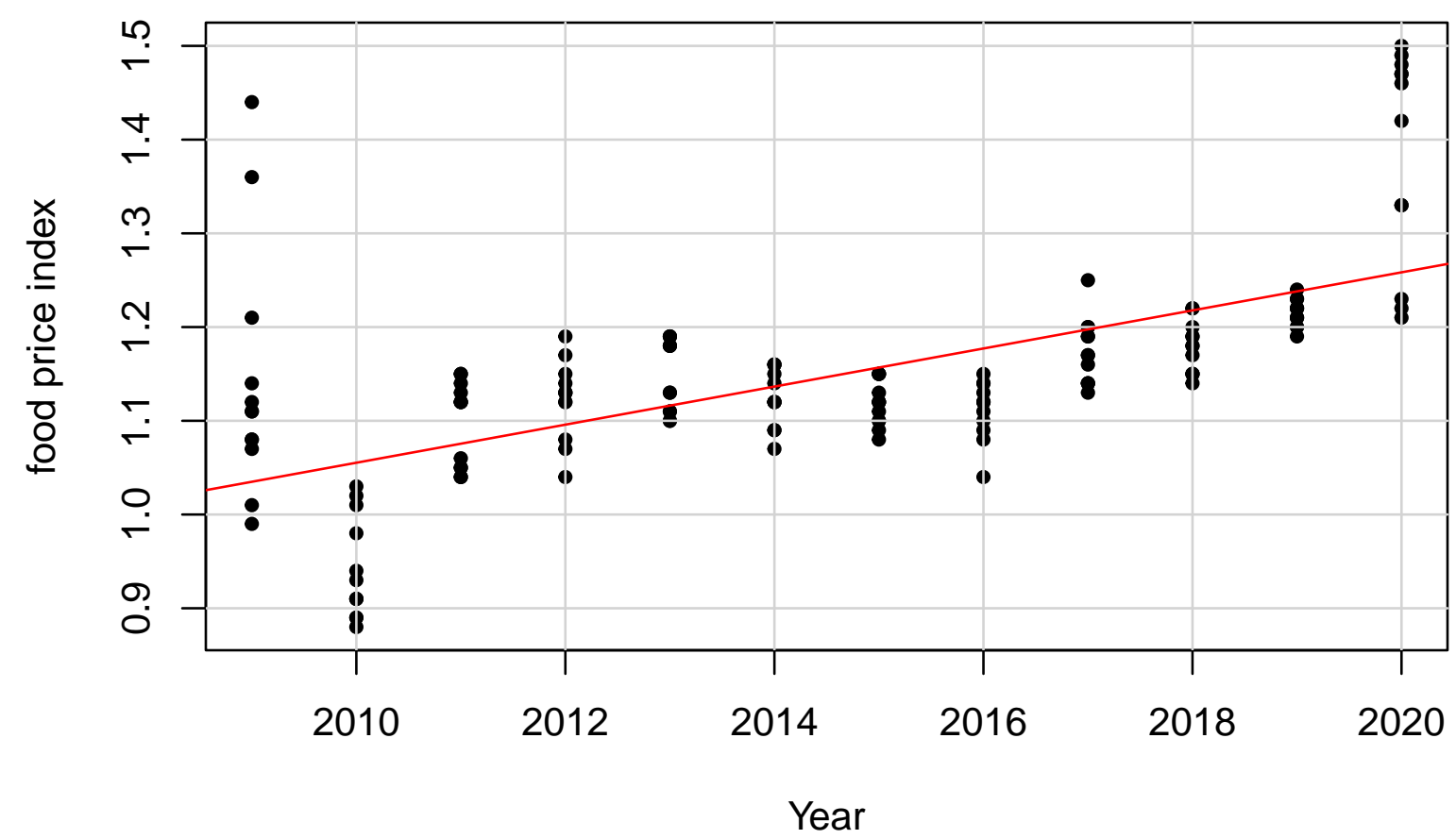

Figure 8: Regression plot for year and food price index (linear model)

Viewing the fitted polynomial regression model: 


\section{Poly-Regression for Food Price Index and Time}

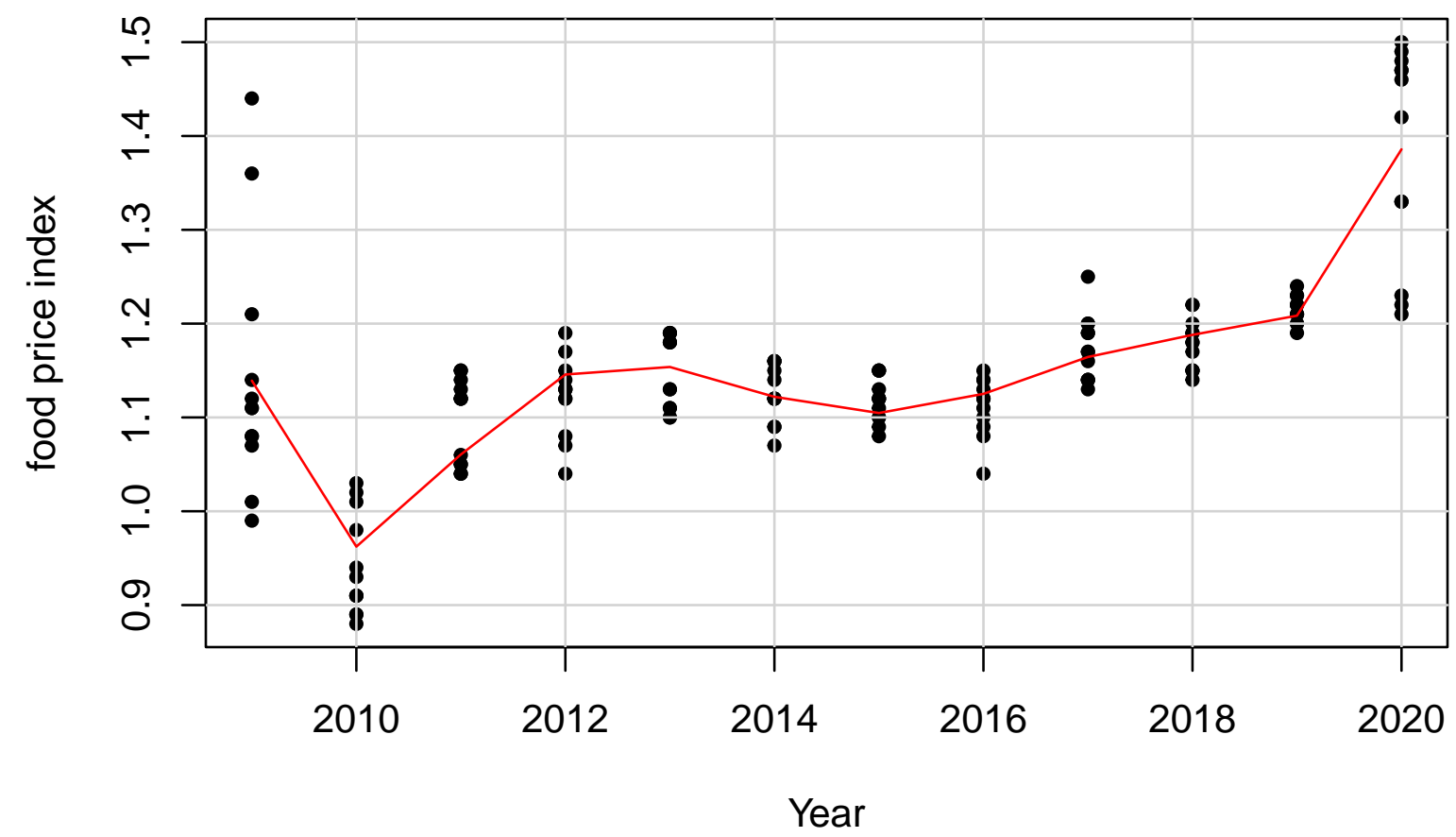

Figure 9: Regression plot for year and food price index (polynomial model)

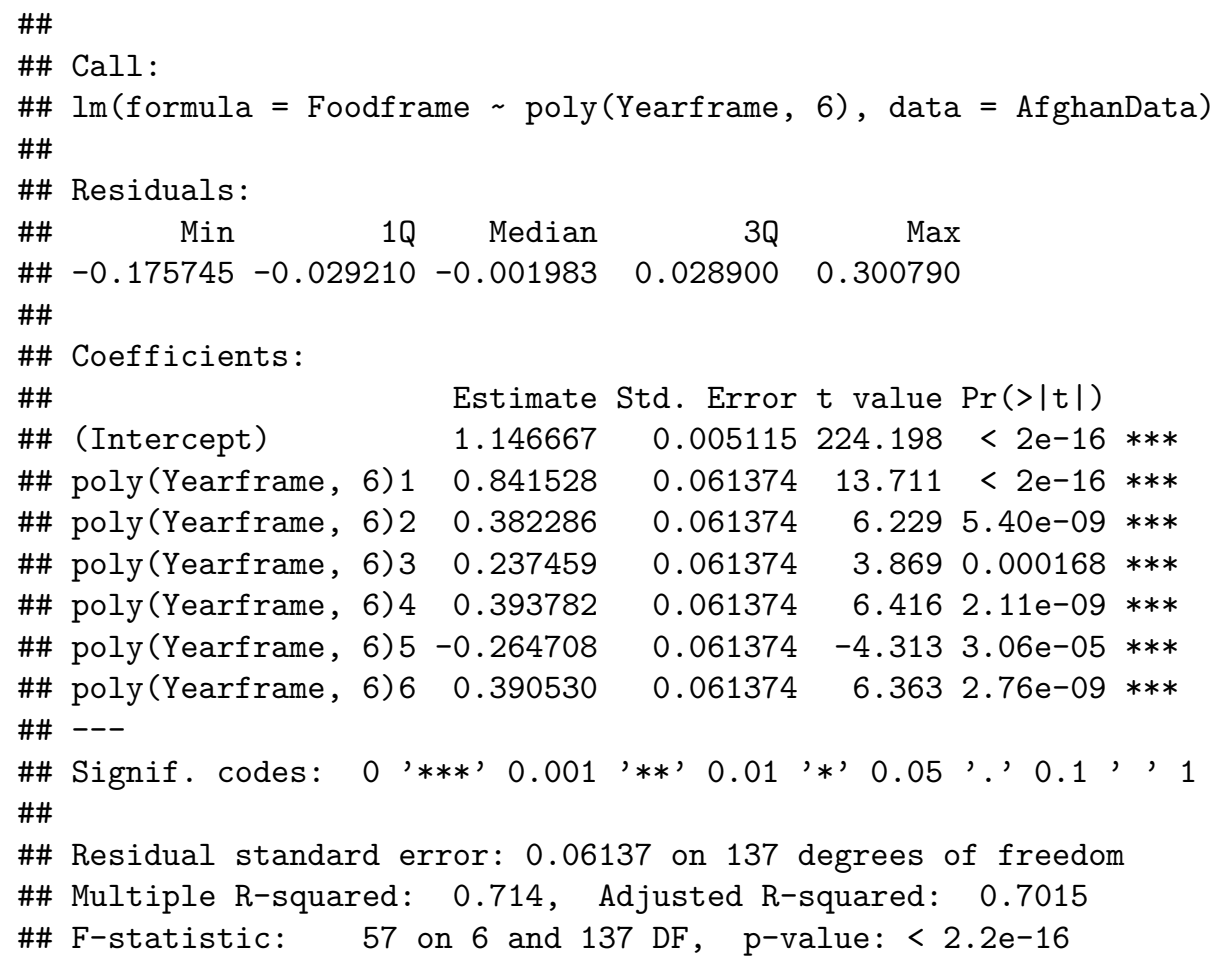

Table 1: Summary of the regression analysis for year and food price index 
From the scatter plot (Figure 8), it is observed that there are linear relationship between year and food price index and outliers are identifies. Though not perfect because of the poly-like scatter plot, a polynomial regression model was fitted (Figure 9). The analysis also show that in each additional one month, their is an associated average increase of food price index of $\mathbf{0 . 3 3}$ and the p-value $\mathbf{2 . 2 e - 1 6}$ which is $<\mathbf{0 . 0 5}$ shows a statistical significant relationship between the year and food price index. It also reveals a $\mathbf{7 1 \%}$ variation between the two variables from the Multiple R-squared (Table 1).

There is a week positive correlation value of $\mathbf{0 . 4 7 4 5 8 6 5}$ between conflict stock displacement and the food price index. This is as a result of an influential outlier in the scatter plot (Figure 10). Eliminating the influential outlier, a perfect linear model was fitted (Figure 11). The analysis reveals that in every single person displaced by conflict, their is an associated average increase of food price index of $\mathbf{7 . 1 3 7 e - 0 8}$ and the p-value $\mathbf{0 . 0 0 4 7 5 9}$ which is $<\mathbf{0 . 0 5}$ shows a statistical significant relationship between the conflict stock displacement and food price index. It also reveals a $\mathbf{6 0 \%}$ variation between the two variables from the Multiple R-squared (Table 2).

There is also a week positive correlation value of $\mathbf{0 . 2 0 3 5 3 4 6}$ between environmental disaster displacement and the food price index. From the scatter plot (Figure 12) observed influential outlier was eliminated (Figure 13). It is observed that there are little or no linear relationship between environmental disaster displacement and food price index. The analysis also show that p-value $\mathbf{0 . 3 0 7 8}$ which is $>\mathbf{0 . 0 5}$ shows no statistical significant relationship between the environmental disaster displacement and food price index. It also reveals a $\mathbf{1 1 \%}$ variation between the two variables from the Multiple R-squared (Table 3).

\section{Linear Regression for Conflict displaced and Food Price}

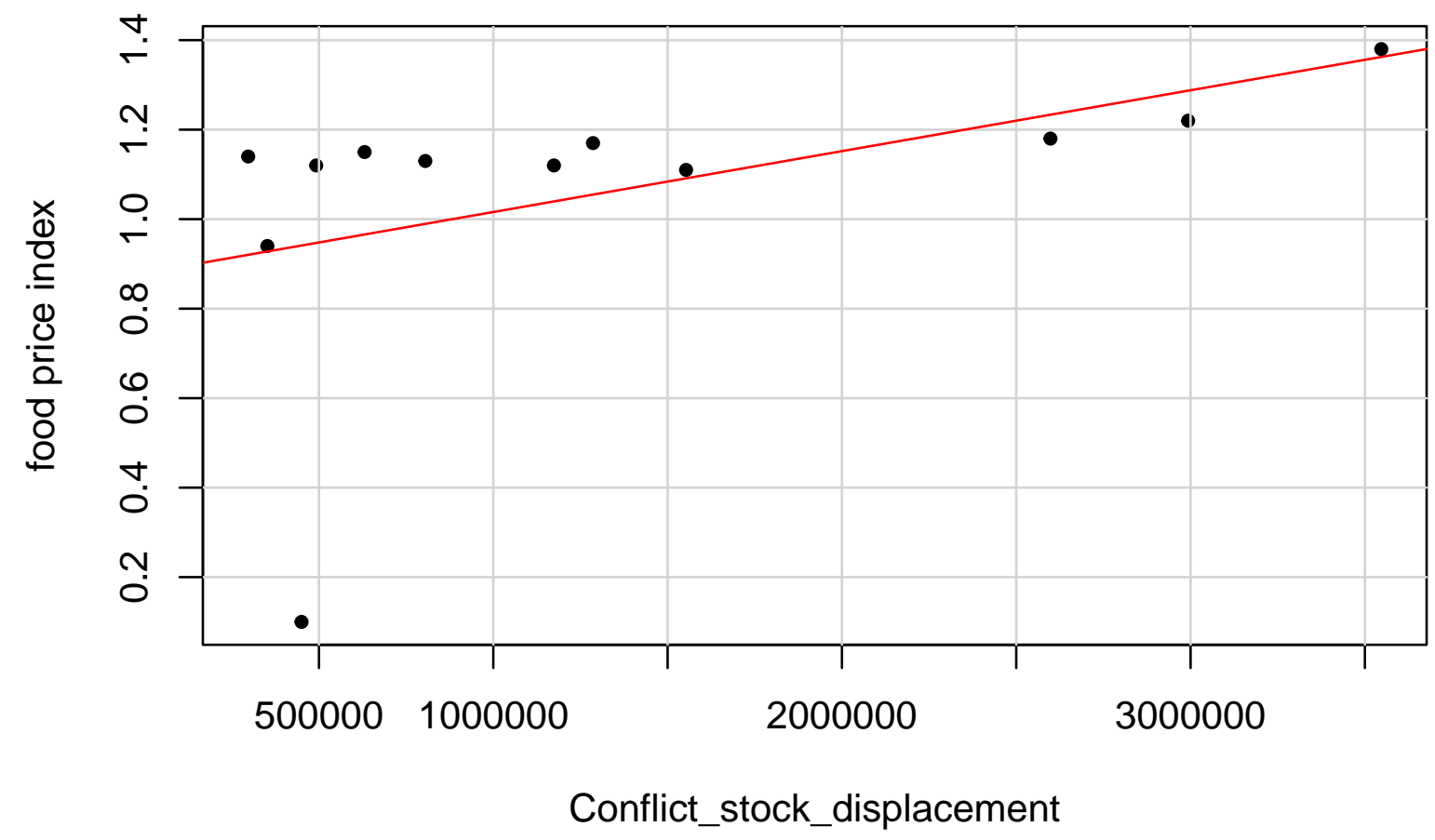

Figure 10: Regression plot for Conflict stock displacement and annual food price index in Afghanistan Eliminating the influential outliers, we get: 


\section{Linear Regression for Conflict displaced and Food Price}

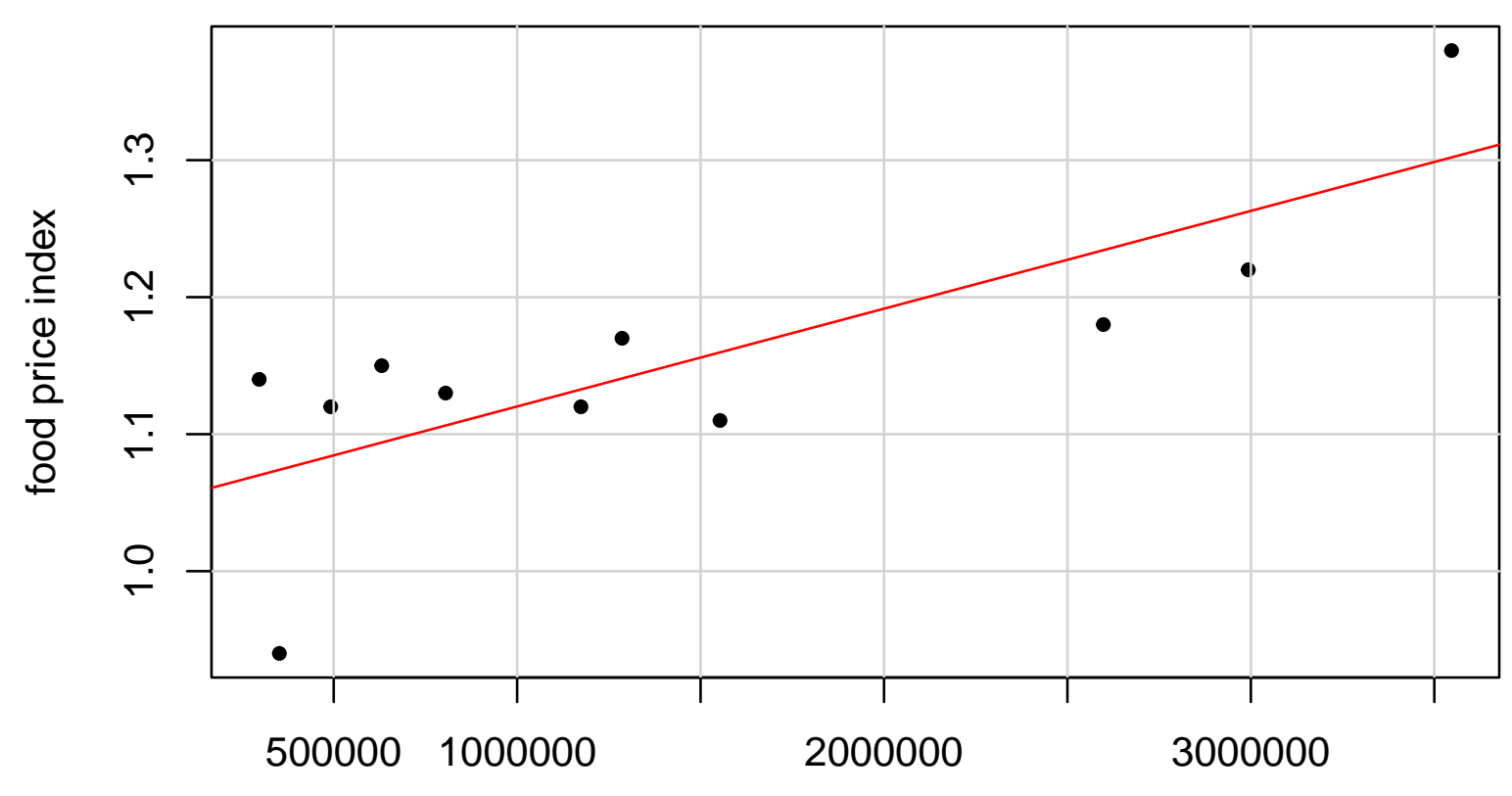

Conflict_stock_displacement[!yout]

Figure 11: Regression plot for Conflict stock displacement and annual food price index in Afghanistan

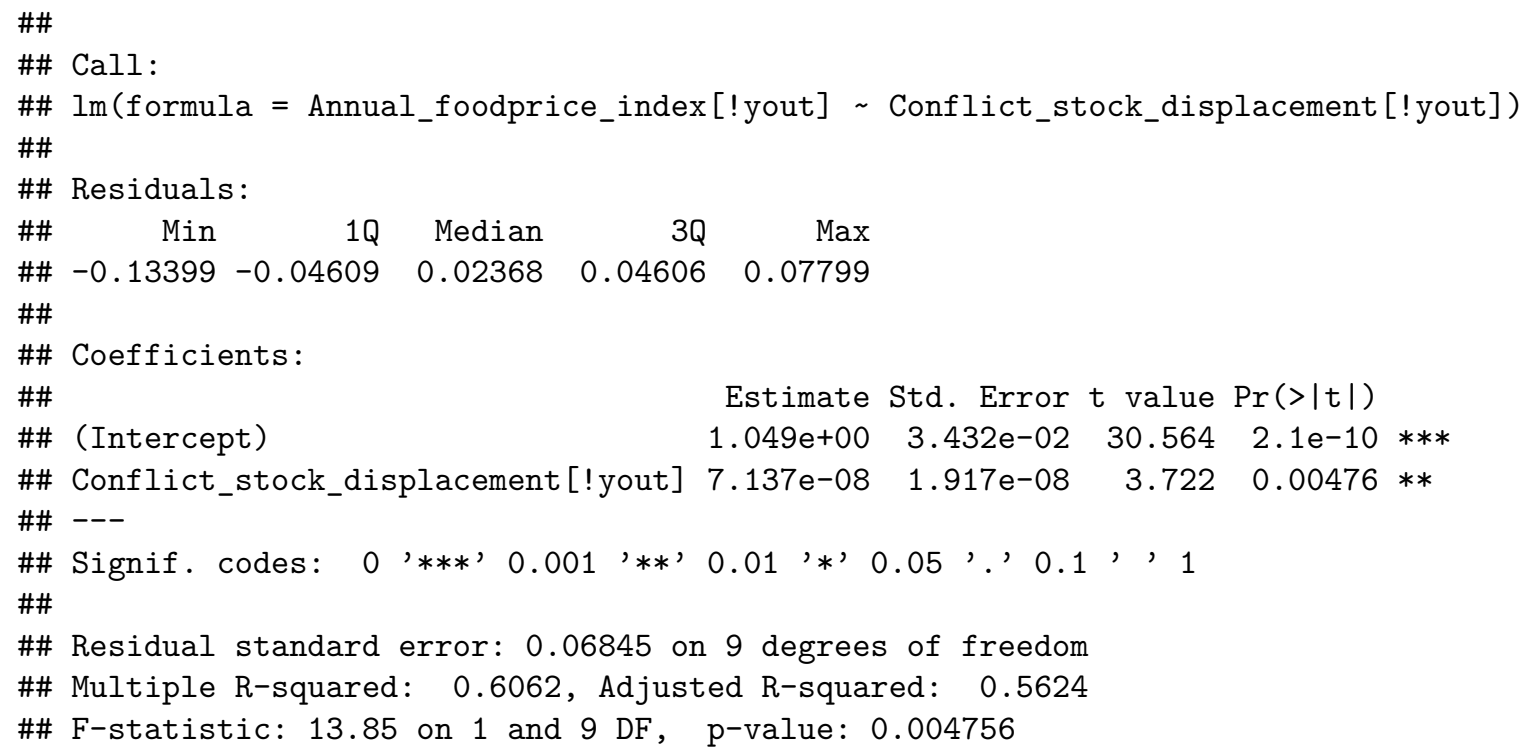

Table 2: Summary of the regression analysis of conflict stock displacement and annual food price index in Afghanistan 


\section{Linear Regression for Env. Disaster Displaced Person and Food Pric}

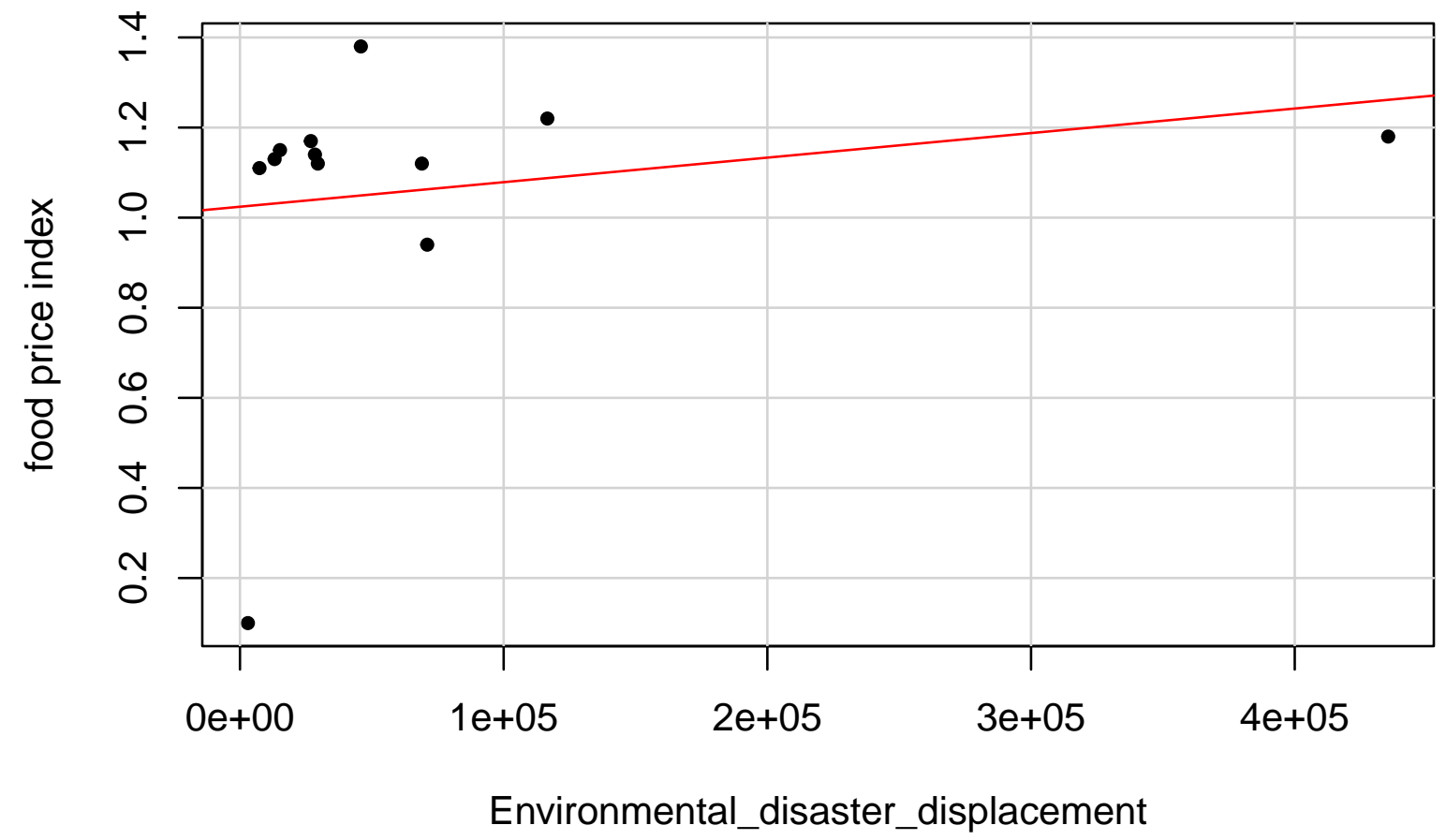

Figure 12: Regression plot for environmental disaster displacement and annual food price index in Afghanistan

Eliminating the influential outliers, we get: 


\section{Linear Regression for Env. Disaster Displaced Person and Food Pric}

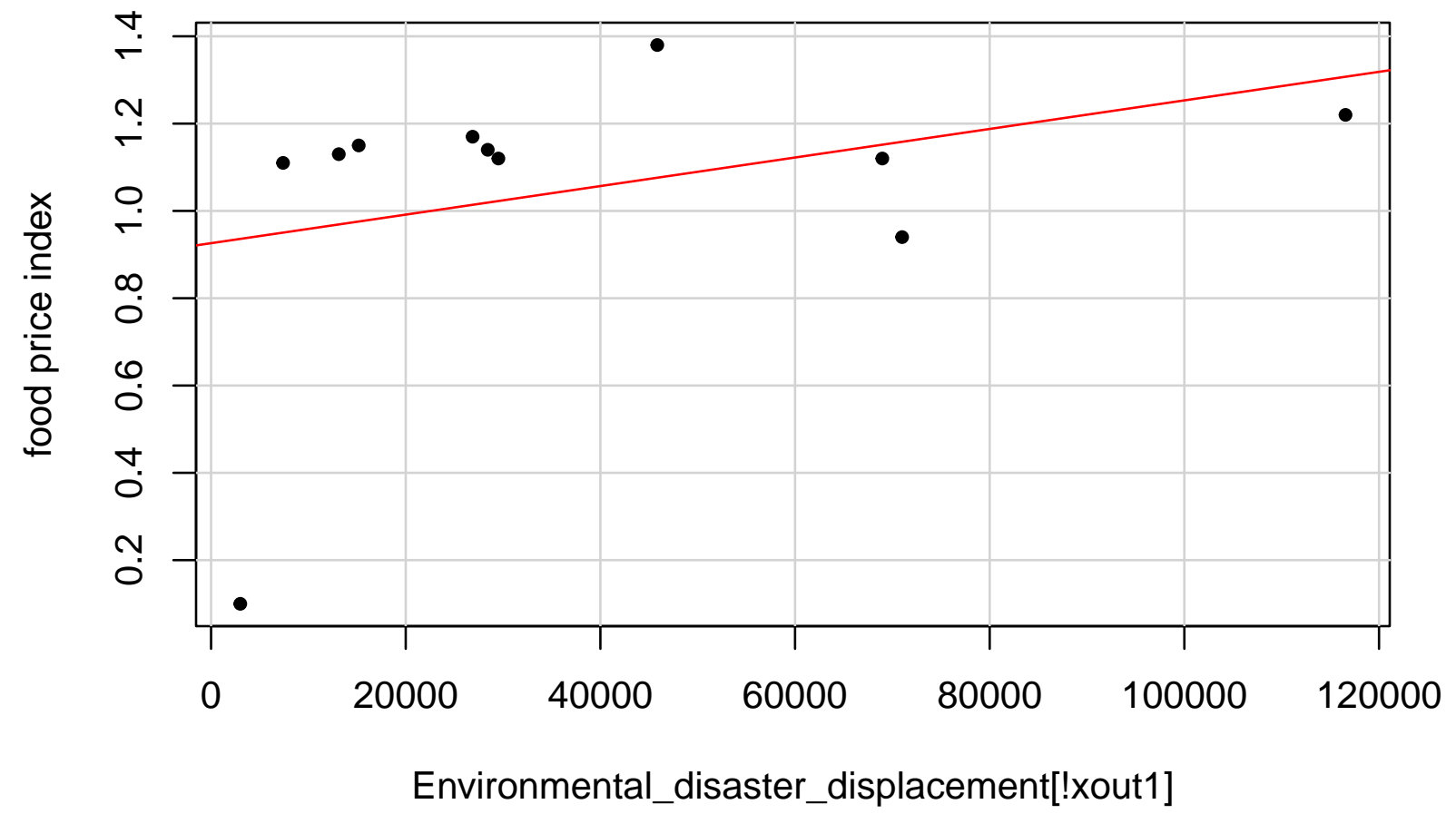

Figure 13: Regression plot for environmental disaster displacement and annual food price index in Afghanistan

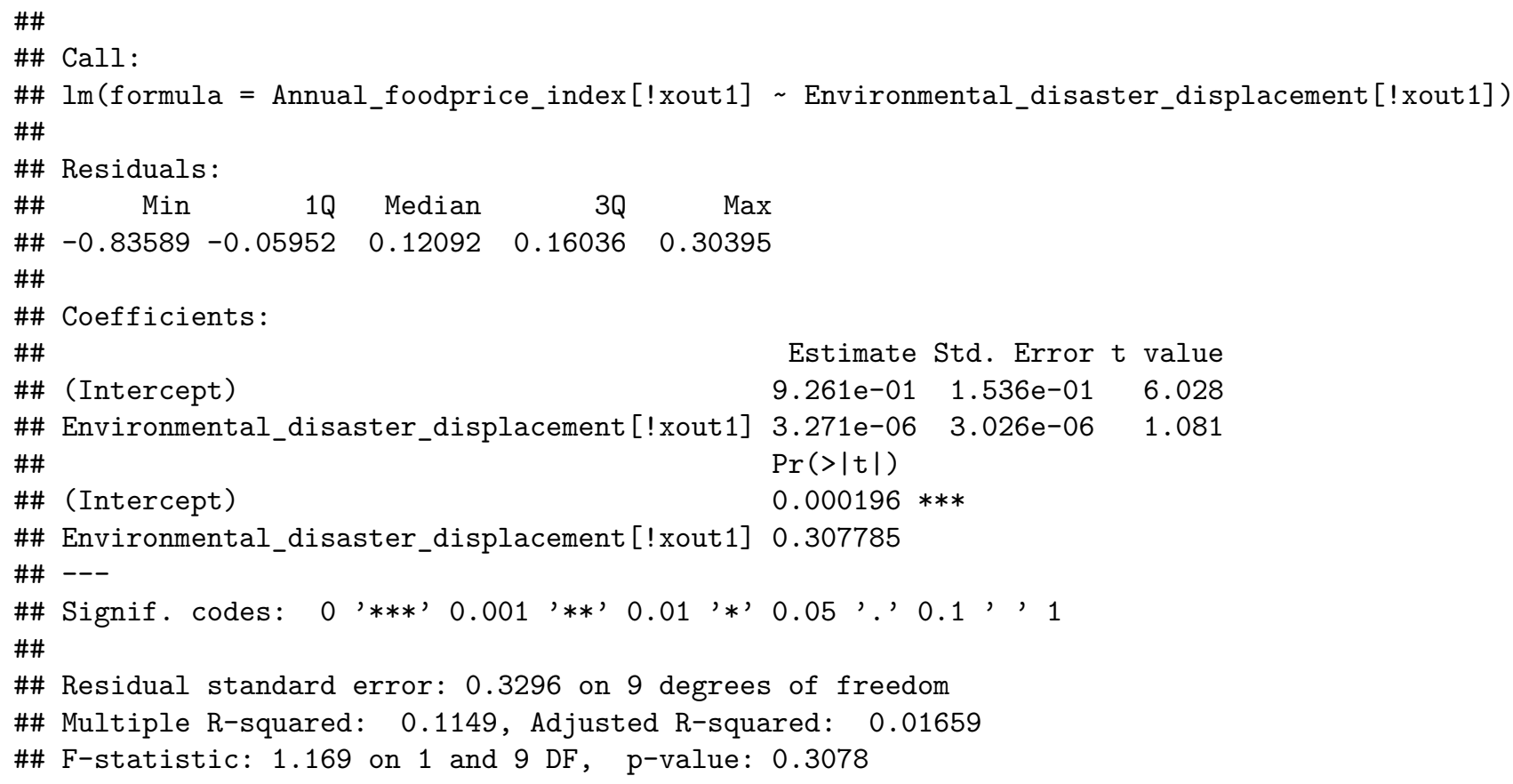

Table 3: Summary of the regression analysis of Environmental disaster displacement and annual food price index in Afghanistan 


\subsection{CONCLUSION}

The increase in food price index in Afghanistan from 2009 to 2020 is proven to be caused by the level of internally displaced persons caused by conflict, but has not impact from environmental disaster. Effective intervention should be put in place by national or international organizations to bring a lasting solutions to issues causing conflict in Afghanistan so as to encourage secure environment for agricultural activities which will effectively mitigate the increase rate of food price. This will enable afghans to come back to their homes and continue their businesses and also production of agricultural products that are basic commodities.

\subsection{REFERENCES}

1. Ahmad, J. M. and Ismat, B., (2018). Agriculture Sector in Economy of Afghanistan. International Journal of Scientific Research and Management. (754-755). Retrieved from: DOI:10-18535/ijsrm/v6: 10.em04

2. Andree, B. P. J. (2021). Monthly Food Price Estimates by Product and Market (Version 2021-1221). COG_2021_RTFP_v02_M Washington, DC: World Bank Microdata Library. Retrieved from: https://doi.org/10.48529/2ZH0-JF55

3. Food and Agriculture Organization of the United Nation (FAO), 2021. FAO Price Data and Analysis. Retrieved from: https://www.fao.org/prices/en

4. Internal Displacement Monitoring Center (IDMC), 2020. Global Internal Displacement Database - 2020 Internal Displacement. Retrieved from: https;//www.internal-displacement.org/database/ displacement-data

5. Tharanga, Y. (2021). Migration and Refugees: The Hidden Economic Cost of Displacement. Inter Press Service News Agency. Retrieved from: https://www.ipsnews.net/2019/02/hidden-economiccost-displacement/

6. Massarath, F., (2019, April 5). Solving the Afghanistan Food Crises. BORGAN Magazine. Retrieved from: https://www.borgenmagazine.com/solving-the-afghanistan-food-crises

7. Mwangi, K., Jideofor, A., Moussa, D., Abigail, J. J., Alpha, K., Temesgen, T. D., Jessica, E. P., and Andrew, W. (2014). The impact of Conflict and Political Instability or Agricultural Investments in Mali and Nigeria: Africa Growth Initiative at Brookings. Paper 17 (8-9, 11-19). Retrieved from: https://www.brookings.edu/wp-content/uploads/2016/06/14-07-22-Impact-of-ConflictMaliNigeria_FINAL.pdf

8. https://microdata.worldbank.org/index.php/catalog/4226/get-microdata 